\title{
Исследование влияния несимметричности геометрии маломодовых кварцевых световодов на дисперсионные характеристики модового состава
}

\author{
$\underline{\text { А.В. Бурдин }}^{1, *}$, В.А. Бурдин ${ }^{1}$, О.Р. Дельмухаметов ${ }^{2}$ \\ ${ }^{1}$ Поволжский государственный университет телекоммуникациий и информатики \\ ${ }^{2}$ Уфимский государственный авиаџионный технический университет \\ *E-mail: bourdine@yandex.ru
}

DOI:10.31868/RFL2018.170-171

В работе представлены результаты теоретического исследования влияния несимметричности геометрии ранее полученного [1] в результате моделирования образца 16-модового оптического волокна (OB) $\mathrm{SiO}_{2}-\mathrm{GeO}_{2}$ с диаметром сердце-

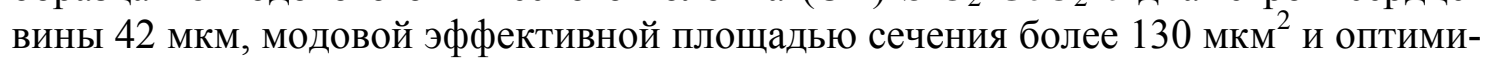
зированной формой градиентного профиля показателя преломления, обеспечивающей снижение дифференциальной модовой задержки (ДМЗ) до 30 пс/км и менее в области оптической несущей $\lambda=1550$ нм и менее 120 пс/км во всем «С»диапазоне длин волн.

Для этой цели предварительно был проведен анализ данных протоколов измерения профилей показателя преломления промышленных образцов одномодовых и многомодовых ОВ разных поколений и рекомендаций ITU-T / категорий ISO/IEC, в том числе и градиентных OB 50/125 кат. OM2+/OM3, оптимизированных для совместной работы с лазерными источниками (LOMF) [2], отличающиеся более строгими требованиями к воспроизведению искомого градиентного профиля ОВ. Как и предполагалось, ключевыми факторами отклонения геометрии ОВ от оптимальной формы, которые возникают в силу особенностей реализации полного цикла технологического процесса промышленного изготовления кварцевых ОВ, включая синтез преформы и процедуру вытяжки строительной длины световода с последующим наложением первичного защитноупрочняющего покрытия, и, соответственно, могут негативно повлиять на дисперсионные параметры модового состава и в целом на деградацию пропускной способности ОВ, функционирующего в маломодовом режиме, являются локальные флуктуации показателя преломления, несимметричность самой формы профиля и непосредственно эллиптичность сердцевины OB.

Так, в результате статического анализа указанных выше протоколов измерений было выявлено, что флуктуации показателя преломления хорошо описываются с помощью нормального закона распределения: здесь локальное математическое ожидание соответствует непосредственно локальному значению показателя преломления, в то время как дисперсия не превышает $5 \cdot 10^{-5}$. Поэтому далее такие флуктуации рассматривались как «нормальные». В свою очередь, для имитации аномально «сильных» искажений профиля дисперсия была увеличена в 3 раза - непосредственно до $15 \cdot 10^{-5}$. Далее с помощью разработанной оригинальной методики, подробно изложенной в [3], была проведена реконструкция 3Dструктуры исследуемого ОВ 42/25 для случая сильных локальных флуктуаций показателя преломления с учетом введенной эллиптичности сердцевины. Здесь вариации радиуса сердцевины относительно значений полярного угла выбирались также в соответствие с протоколами измерения профилей промышленных образцов LOMF, пропорционально масштабированные на усредненный радиус сердцевины 21 мкм, которые в данном случае достигали до 0.4 мкм. Затем для каждой условной «четверти» радиального сечения ОВ также проводился расчет 
дисперсионных параметров модового состава и далее - спектральных характеристик ДМЗ с помощью ранее разработанной модификации приближения Гаусса [4], обобщенной на случай анализа ОВ с увеличенным диаметром сердцевины и произвольной формой профиля показателя преломления.

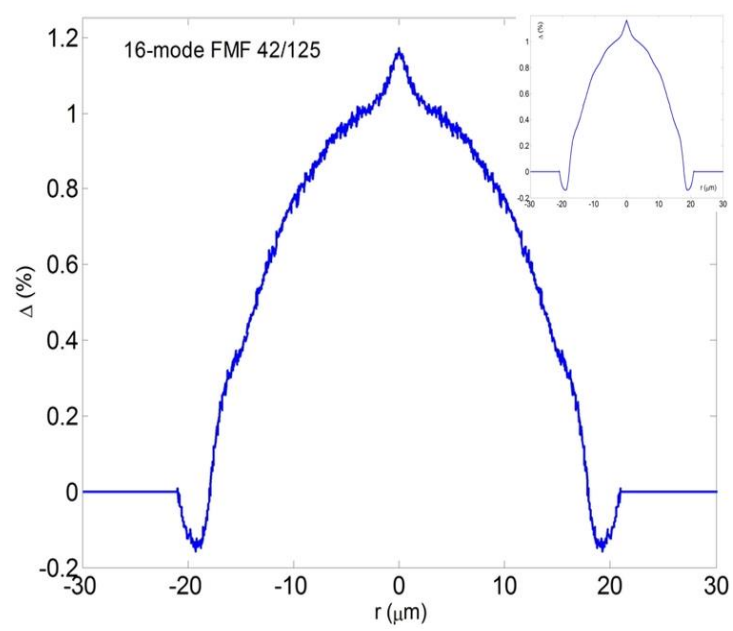

Рисунок 1 -градиентный профиль 16-модового ОВ 42/125 с наложением сильных локальных флуктуаций показателя преломления

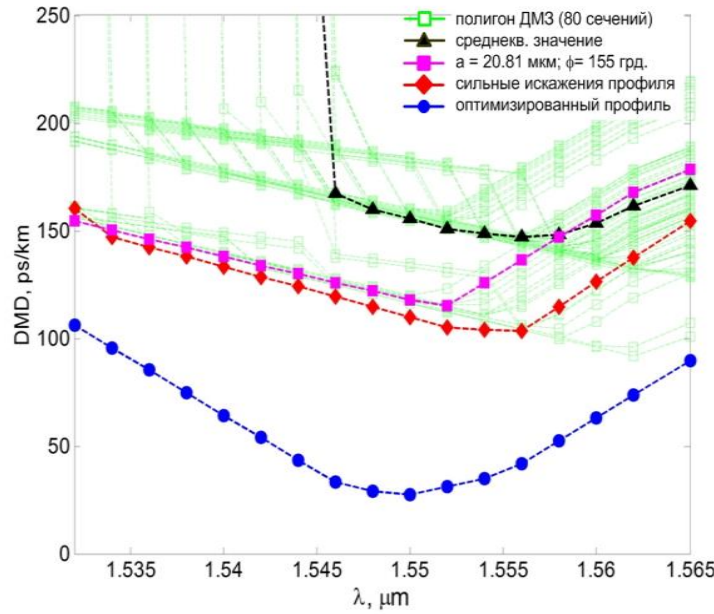

Рисунок 2 - Спектральные кривые ДМЗ в «С»диапазоне длин волн для оптимизированной и несимметричной формы профиля ОВ 42/125

На рис. 1 представлен образец профиля показателя преломления 16модового FMF 42/125 с «наложением» аномально сильных локальных флуктуаций показателя преломления. На рис. 2 - спектральные характеристики ДМЗ в «С»-диапазоне длин волн, построенные для модельного ОВ круглого сечения с оптимизированной формой профиля показателя преломления, аномально сильно «искаженной», а также полигон для 80 «четвертей» радиальных сечений несимметричного ОВ также с аномально сильно «искаженным» профилем и эквивалентна кривая среднегеометрического значения ДМЗ. Анализ полученных результатов показывает, что, в отличие от случая, соответствующего ОВ круглого сечения с аномально сильными локальными флуктуациями показателя преломления, деградация спектральной характеристики ДМЗ проявляется намного сильнее при наличии эллиптичности геометрии ОВ. Фактически разброс радиуса сердцевины от искомого значения 21 мкм даже на 0.4 мкм при одновременном наличии сильных локальных флуктуаций показателя преломления приводит к появлению новых модовых составляющих в области «коротких» длин волн «С»-диапазона, что неизбежно увеличивает ДМЗ до неприемлемо высоких значений - вплоть до 1.3 нс, и при этом может ухудшить спектральную характеристику ДМЗ в области «длинных» волн этого же диапазона на 50 пс/км относительно спектральной кривой, учитывающей только сильные искажения профиля без эллиптичности сердцевины

Исследование выполнено при финансовой поддержке РФФИ в рамках научного проекта № 16-37-6001515 мол_а_дк

\section{Литература}

[1] V.A. Andreev, A.V. Bourdine et al., Proceedings of SPIE 10342, 1034207-1 - 1034207-8 (2016)

[2] А.В. Бурдин, К.А. Яблочкин, Инфокоммуникачионные технологии 2, 22 - 27 (2010)

[3] A.V. Bourdine, V.A. Burdin et al. Proceedings of SPIE 10774, 10774-08-01 - 10774-08-011 (2017)

[4] A.V. Bourdine, Advances in Optical Technologies 2013, 469389-1 - 469389-18 (2013) 